1970) have been able to demonstrate the intimate relationship between microearthquakes and the San Andreas fault to show that microearthquakes can be used to map active faults and to determine the depth to which stick-slip motion extends. Quite apart from their intrinsic academic interest, these and similar studies are of considerable importance in the search for viable prediction techniques along the San Andreas fault and its associated faults. Members of the US Geological Survey's National Center for Earthquake Research have discovered, for example, that microearthquakes play a significant part in releasing tectonic strain as it builds up. In other words, the real danger zones are those where microearthquakes are now known to be rare and where an unmitigated build-up of strain can be expected to culminate in one or more extremely large events.

The San Andreas fault zone may be fairly regarded as an atypical part of the world rift system; and, in a rather different sense, so may Iceland, where Ward et al. (J. Geophys. Res., $74,665 ; 1969)$ deployed portable seismographs at seventy-eight sites to monitor microearthquakes during the summer of 1967. Iceland, of course, has never been studied as intensively as the San Andreas region, so at the time that Ward and his colleagues began their work it was not even possible to plot the course of the MidAtlantic Ridge through the country with any degree of certainty. Ward et al. were therefore able to apply the statistical advantages of microearthquake investigation to a relatively unknown situation and, in so doing, were able to propose the existence of two transform faults within Iceland and plot their positions with some conviction. Subsequently, Molnar and Aggarwal (Bull. Seismol. Soc. Amer., $61,195 ; 1971)$ successfully used similar instruments and techniques in the Kenyan section of the East African rift.

But the three examples quoted so far have been based on land areas where access is relatively free. Any attempt to extend such studies to the ocean bottom, where, after all, the world rift system is at its most "typical", clearly poses additional practical problems. The MidAtlantic Ridge far from Iceland is a good case in point. As Francis and

Porter point out on page 547 of this issue of Nature, accurate correlation of seismicity and physiography has hitherto not been possible because of the crudity of epicentral location far from continents; depth determinations have been limited, on the whole, to qualitative descriptions such as "shallow". The need is clearly for seismographs on the ocean floor if any further progress is to be made in the detailed seismological study of ridge axes.

Instruments for ocean bottom seismology have been under development for some time, although as recently as 1970 one author pointed out that such instrumentation is only in its early stages. Three basic approaches have been tried. In the first, a sealed seismograph is lowered to the ocean floor from a ship and the seismic signals are telemetered back to the ship by cable. The disadvantage of such a physical link is the obvious one - that motions of the ship and the connecting cable tend to be transmitted to the instrument. The technique has, however, been used with some success on the floors of the Black Sea and the Baltic by Soviet seismologists. The solution to this problem is to replace the cable by an acoustic link, and this, too, has been made to work successfully. A third

\title{
Temperature Sensitive Mutant Mammalian Cells
}

THE isolation and characterization of conditional lethal mutants has been a cornerstone of the analysis of metabolic pathways in bacteria and several groups are currently attempting to isolate temperature sensitive mutants of mammalian cells growing in culture and then to use them to analyse such processes as DNA replication, transcription, mitosis and so on.

It has already become apparent that many cultivated cells with mutated phenotypes have high reversion rates which not only hinder biochemical analyses but also raise questions as to the nature of the genetic changes which lead to the changed phenotype. Chromosomal and therefore gene dosage effects may, for example, be important. But as Naha reports in Nature New Biology next Wednesday (January 3) it is possible to select clones of African green monkey kidney BSC 1 cells that are temperature sensitive for cell proliferation and have reversion frequencies of less than $10^{-5}$.

Naha has, apparently, isolated eight such mutant clones which can be classified into three groups by virtue of their phenotypes at the non-permissive tem- method involves the use of a selfcontained detecting and recording package which is dropped to the ocean floor and subsequently recovered for analysis at an appropriate time.

In Britain, an ocean bottom seismograph developed jointly in recent years by the Institute of Geological Sciences and the UK Atomic Energy Authority adopts the third of these approaches, although a subsidiary instrument-to-ship acoustic link is used for position measurement. Francis and Porter describe microearthquake data obtained from the first deployment of two of these instruments-one of which was dropped some $30 \mathrm{~km}$ to the east of the median valley of the Mid-Atlantic Ridge and one of which was placed in the median valley itself. The results are, of course, preliminary, but two things are already clear. The first is that because of the characteristics of the ridge zone, the best results will only be obtained from arrays of seismographs with instrument spacings of less than $10 \mathrm{~km}$. The second is simply that the deployment of such arrays, as on land, will pay handsome dividends in terms of data from what is one of the key zones of the new global tectonics.-From our Geomagnetism Correspondent. perature $\left(39.5^{\circ} \mathrm{C}\right)$. The first group of mutants is defective in thymidine metabolism; the second group is defective in uridine metabolism and the third group is defective in both thymidine and uridine metabolism. These lesions reduce by more than ten-fold the plating efficiencies of the cells at $33^{\circ} \mathrm{C}$ after they have been held for $12 \mathrm{~h}$ in $39.5^{\circ} \mathrm{C}$ and from analyses of cell generation times Naha concludes that it is likely that mutants of the second and third groups are blocked early in the G1 phase and mutants of the first group are blocked in the $S$ phase of the cell cycle.

Analysis of the fate of ${ }^{3} \mathrm{H}$-thymidine incorporated during a 30 minute pulse at $39.5^{\circ} \mathrm{C}$ indicates that TTP accumulates in these cells which are blocked in DNA synthesis and the decrease in viability with time at the non-permissive temperature suggests that the defects they carry become irreversible. Precisely which steps in the pathway to DNA synthesis are defective remains to be seen; as Naha comments, it also will be particularly interesting to see if infection by $S V 40$ at $39.5^{\circ} \mathrm{C}$ overcomes the block to DNA synthesis in these cells. 